\title{
A Study on Use of Mathematical Programs for Design of Electronic Circuits in Cybernetic-Physical Learning Environment
}

\author{
Namrata Dewan Soni, Jyoti Bhola, and Mona Bhatnagar
}

\begin{abstract}
The laboratory work holds a great importance for an undergraduate student of science. And during COVID -19 pandemic, when the theory classes were moved online, migrating practical classes to online mode turned out to be a challenging task. This article aims to study the use of mathematical programs as an extensive methodological approach to enhance the learning of electronic circuit designing at undergraduate level. The students were given a task of designing a well-known oscillator circuit using a mathematical program written in open source application Scilab. The values of all the components needed to design an oscillator were calculated. The circuit was then designed practically for various frequencies using the theoretically obtained component values. The obtained output frequency of oscillator circuit was within $5 \%$ variation to the theoretically obtained one. In this article, the authors captured the experience of 500 undergraduate science students studying at various colleges of University of Delhi, India via a valid online questionnaire circulated through different platforms. The response of the students was gauged and it could be inferred that mathematical programs are working as a decent replacement during these demanding times and can be used as an add-on, once the physical labs start operating back to normalcy.
\end{abstract}

Index Terms-Education, phase shift oscillator, Scilab.

\section{INTRODUCTION}

The clamping of lockdown due to COVID-19 pandemic led to a world-wide abrupt shift of face to face teachinglearning process to online mode in schools as well as colleges The remote learning became a reality during the global lockdown by virtue of various platforms like Google meet, MS Teams, Zoom, etc. These tools are now being widely used to deliver lectures, take tutorials and carry out assessment task [1]-[4]. But for science students, particularly Physics and Electronics, the course curriculum also mandates performing practicals in laboratories [5]. The laboratory work aims to provide an opportunity to acquire hands on experience of working on various complex instruments while designing and studying different circuits [5]. The traditional way of teaching practical component of circuit theory to undergraduate students is to give them specification of the circuit to be designed [6]. Using the theoretical background of the circuit and the equations involved, the students solve

Manuscript received February 20, 2021; revised June 13, 2021.

Namrata Dewan Soni and Mona Bhatnagar are with the Department of Physics and Electronics, Hansraj College, University of Delhi, Delhi-110007, India (corresponding author: Namrata Dewan Soni; e-mail: ndsoni@hrc.du.ac.in,monabhatnagar65@gmail.com).

Jyoti Bhola is with the Department of Mathematics, Hansraj College, University of Delhi, Delhi-110007, India (e-mail: jbhola.24@gmail.com). the task and problems in circuit theory. But, if there is any error in the calculations, then the designed circuit may not work for given specification or it may burn out [7], [8]. These issues were somehow addressed with the use of simulation tools like LT spice, PS spice, etc. as a prelab assignment [7]-[9]. Some of the limitations of using these simulation software are requirement of shareware license, subscription cost (as some of them are not free to use) and an additional burden to learn these tools, as these are not a part of science undergraduate curriculum [10]-[12]. Computer programming is one of the important papers that a science undergraduate student studies in the course curriculum and this tool has been exploited well earlier by many researchers in designing various electronic circuits [10]-[12]. Thus to avoid the anticipated mistakes, save upon the limited resources available in the laboratories [13] and foresee the results of the circuit to be designed, mathematical programs can prove to be of significant help [10]-[12]. This realization could be made during the COVID-19 pandemic times when the physical lab work was transferred to virtual labs that provides pre-lab, in-lab and post-lab requisites for the remote conduct of the practical work [1], [14]. To make the virtual lab learning effective, it is very important for the student to be familiar with the theoretical paradigm being employed to work out the problem and to build clarity into what to look for.

This is illustrated in the present work through a task of circuit designing given to Physics and Electronic Science undergraduate students. They were asked to design a transistor based circuit of phase shift oscillator of given frequency with the help of a mathematical program. The oscillator circuit is chosen in present study as it is an integral part of the curriculum of both Physics and Electronic Science courses at undergraduate level.

Phase shift Oscillator is a well-known sinusoidal audio oscillator since long time [15], [16]. Phase shift oscillator circuit is a low frequency oscillator circuit that has a number of applications in musical instruments, GPS units and voice synthesis [15]-[17]. And for this reason, it is one of the important practicals to be carried out by the undergraduate Physics and Electronics students. The challenge that students at undergraduate level face is to design an oscillator circuit that works at the desired frequency. Many circuit designers use either complex mathematical procedures or an expensive (and inaccessible for most of us) computer aided design (CAD) technique to design the transistor-based phase shift oscillator [18], [19]. These advanced techniques strengthen the conceptual knowledge in students through enhanced graphical aids and interactive simulations [20], [21]. Since these advanced techniques are not a part of the student 
curriculum, so investing extra time in learning the use of these tools can turn out to be burdensome for students [5]. Also, these are expensive tools and their maintenance on an accessible computer is a projected problem [20], [21]. More so, particularly during this pandemic time, the remote use of these tools is not possible. On the other hand, Scilab practicals are an integral part of undergraduate science curriculum. So students are familiar with the use of Scilab programming. Since this is an open source platform, a student can comfortably use it for circuit analysis and designing, without putting any extra effort and time in learning the concept.

This paper provides a simple step-by-step method that will enable the students to design an oscillator circuit. A program written in Scilab to calculate the component values of various components like resistors, capacitors, etc. to be used in phase shift oscillator circuit operating at desired frequency is presented. The program also shows the wave output of the designed phase shift oscillator circuit. Using the values obtained from the program, the circuit for the given specification was actually realized in the laboratory. The results obtained from practical realization of the circuit were in line with the ones obtained using mathematical program.

The mathematical code can be written easily for various circuits to be studied and designed at undergraduate level with in open source environment Scilab. The students were asked to share their experience regarding the use of mathematical program in the designing of the circuit through an online questionnaire. The outcomes reflect the possibility of introducing the use of mathematical programs before actually realizing the circuit in laboratories. This methodological technique tends to not only save time and limited resources, but also equip the students with circuit designing techniques and help them visualize the output graphically prior to realizing it practically. This has also proven to be a savior in teaching-learning of designing concept in the COVID-19 pandemic times where the practical learning in physical laboratories has essentially come to a halt.

\section{THEORY AND PROCEDURE}

To analyze the potential use of simple mathematical programs as a methodological tool in the designing and analysis of electronic circuits, Physics and Electronics undergraduate students studying at various colleges of University of Delhi were given a task to design a basic transistor based phase shift oscillator circuit operating at given frequency with the help of a mathematical program written in Scilab platform.

Fig. 1 explains the step wise procedure followed in the present study to capture the response of students' experience of using mathematical programs in design and analysis of electronic circuits.

The basic circuit of a transistor-based phase shift oscillator is shown in Fig. 2 [15]-[16]. It comprises of a single stage common emitter (CE) amplifier working in voltage divider configuration with a positive feedback through RC networks as shown in Fig. 2. The resistances $R_{A}, R_{B}, R_{C}$ and $R_{E}$ provide base and collector bias. The capacitor $C_{E}$ bypasses the emitter resistor $R_{E}$ and prevents any AC feedback. The task was to calculate all these component values $\left(R_{A}, R_{B}, R_{C}, R_{E}, C\right.$ and $C_{E}$ ) for the circuit to operate at a given frequency.

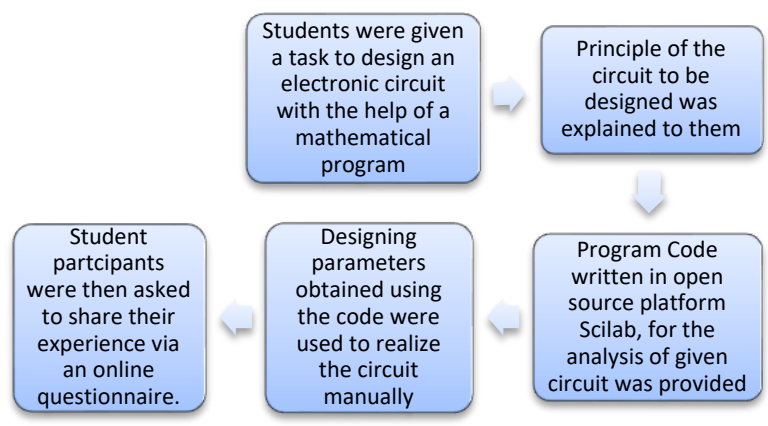

Fig. 1. Research flowchart of the present study.

The basic principle of transistorized phase shift oscillator circuit is that the transistor bias in common emitter configuration introduces a phase difference of $180^{\circ}$ between the base and collector voltage. The additional phase shift of $180^{\circ}$ is provided by frequency selective RC networks to make a total phase shift of $360^{\circ}$ which is the prime requirement for the oscillations to occur [15], [16].

When the power is applied to the circuit, noise (these are random electrical variations generated internally in any electronic component especially due to motion of electrons) is generated. These noise signals result in a change in flow of base current. This change in base current produces an amplified change in collector current which is shifted by $180^{\circ}$. When the signal is returned to the base, it is shifted in $180^{\circ}$ phase by $\mathrm{RC}$ network. However, this positive feedback is experienced by only one frequency and only that frequency is amplified [15], [16].

The expression for that frequency of the circuit is then given by [15]

$$
f_{o}=\frac{1}{2 \pi R C \sqrt{6+\frac{4 R_{C}}{R}}}
$$

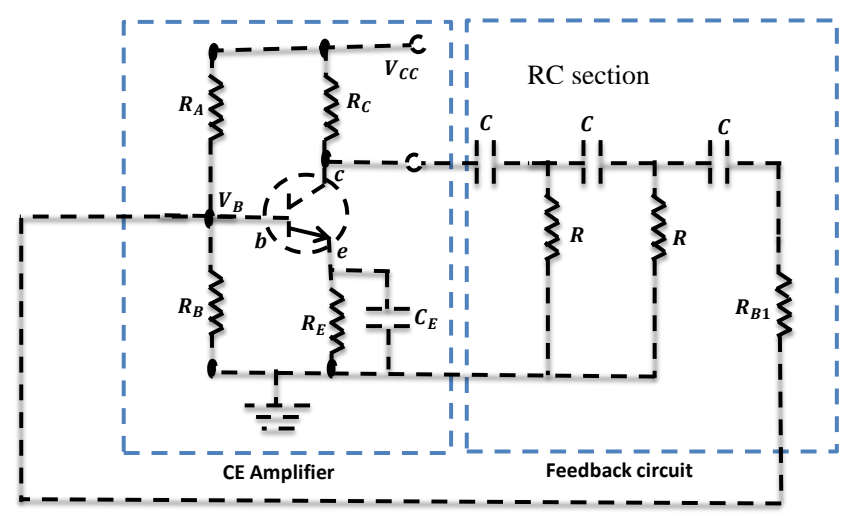

Fig. 2. Basic circuit of transistor-based phase shift oscillator.

Apart from providing the required phase shift, $\mathrm{RC}$ section in the circuit also acts as an attenuator. With the passage of the signal through each successive section in the RC ladder, the signal reduces by some amount and becomes (-1/29) across all the three stages. The condition on the gain of the $\mathrm{CE}$ amplifier to have sustained oscillations is given by [22]. 


$$
h_{f e}=\frac{29 R}{R_{C}}+23+\frac{4 R_{C}}{R}=\frac{R}{R_{C}}\left(29+\frac{23 R_{C}}{R}+\frac{4 R_{C}^{2}}{R^{2}}\right)
$$

$$
\text { for } \frac{R_{C}}{R} \ll 1, A \geq\left(h_{f e} \frac{R_{C}}{R} \cong 29\right)
$$

To compensate for this passive RC loss, it is required to have a voltage gain of the transistor amplifier, sufficiently higher than 29 [22].

Even though the working principle of the circuit is easy, but the involvement of so many components in the circuit makes it complicated to design. The unnoticed effective input and output resistance of the CE amplifier circuit plays an important role in determining the starting condition and the oscillation frequency of the oscillating circuit. Moreover, the stability factor of CE amplifier plays an important role in the circuit design. The stability factor for voltage divider bias configuration is given by [22],

$$
S=\frac{1+\beta}{1+\frac{\beta R_{E}}{R_{T H}+R_{E}}}
$$

where,

$$
R_{T H}=\frac{R_{A} R_{B}}{R_{A}+R_{B}}
$$

Now to find the component values of the different components used in the oscillator circuit shown in Fig. 2, we apply Kirchoff's Voltage law (KVL) across the input and output circuit. Using KVL, we have input voltage at base $V_{B}$ given by:

$$
V_{B}=\frac{R_{T H}}{R_{A}} V_{C C}=V_{b e}+I_{E} R_{E}
$$

where $V_{C C}$ is the supply voltage, $V_{b e}$ is the voltage drop across base-emitter junction, $I_{E}$ is the emitter current (nearly equal to collector current $I_{C}$ ).

Applying KVL round the output circuit gives

$$
V_{C C}=I_{C} R_{C}+V_{c e}+I_{E} R_{E}
$$

Thus, the circuit can be designed for the desired frequency using Eqs. (2), (3) and (4) in Eqs. (5) and (6).

A program is written in open source Scilab to obtain the values of the components used to realize the PSO circuit operating at a given frequency. The code also depicts the output of PSO circuit and the output voltage is expressed as [23], [24]:

$$
V_{\text {out }}(t)=\left( \pm V_{S A T}+28 V_{i}\right) \operatorname{Cos}\left(\omega_{o} t\right)-28 V_{i}
$$

\section{SimUlation}

To design the basic transistor-based phase shift oscillator circuit given in Fig. 2 and operating at a desired frequency, parameters and components mentioned in Table I were chosen.

A code is written in scilab to calculate the component values of $R_{A}, R_{B}, R_{C}, R_{E}$, and $C_{E}$. The code also depicts the output of the oscillator circuit designed using these components [22]. The transistor used in the circuit and the associated values of $h_{f e}$ and $h_{i e}$ can be easily changed in the code given in Fig. 3 and the circuit can be re-simulated. In the present case we have used transistor $B C 547 B$ with input resistance $\sim 4.5 \mathrm{k} \Omega$ and gain $\sim 330$. The components of the circuit are calculated for firing voltage of $10 \mathrm{~V}$ and frequency output of $2 \mathrm{KHz}$.

TABLE I: DETAILS OF THE COMPONENTS/PARAMETERS CONSIDERED TO DESIGN PSO CIRCUIT

\begin{tabular}{|l|l|}
\hline Transistor used & BC 547 B \\
\hline$h_{i e}$ & $4.5 \mathrm{k} \Omega[25],[26]$ \\
\hline$h_{f e}$ & 330 \\
\hline Stability factor & 10 \\
\hline
\end{tabular}

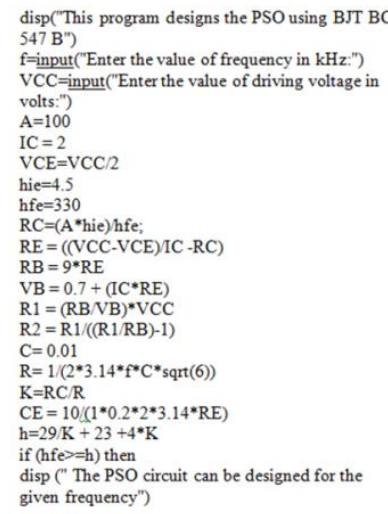

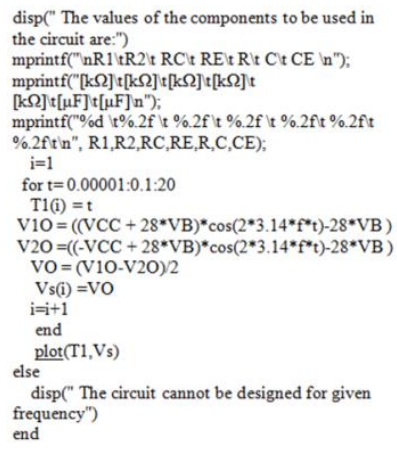

Fig. 3. Scilab simulation code.

Fig. 4 shows the output obtained from simulation. The code provides the values of all the components used in designing the PSO circuit to generate a frequency output of $2 \mathrm{kHz}$ and it also shows the output waveform.
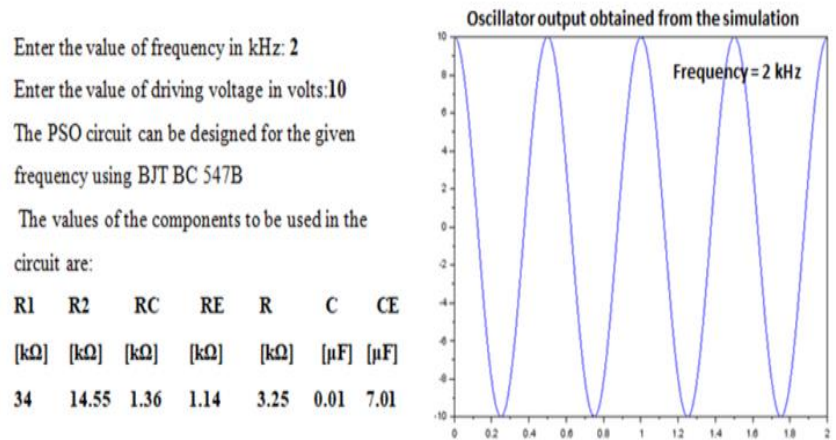

Fig. 4. Component values and oscillator output obtained from simulation for $\mathrm{f}=2 \mathrm{kHz}$.

\section{EXPERIMENTAL}

The circuit given in Fig. 2 is realized for different frequencies using transistor $B C 547 B$ and the component values calculated with the code given in Fig. 2. The values of $R_{A}, R_{B}, R_{C}, R_{E}$, and $C_{E}$ obtained theoretically are presented in Table II. For the implementation of the PSO circuit the actual values of $R_{A}, R_{B}, R_{C}, R_{E}, a$ nd $C_{E}$ used were chosen to be nearest to the standard values available. These are mentioned in brackets in each row below the theoretically obtained ones in Table II.

The output voltage $V_{\text {out }}(t)$ and the frequency of the output wave of the circuit were measured using Agilent Technologies DSO 1052B. The oscillator circuit is designed for five different frequencies viz $400 \mathrm{~Hz}, 500 \mathrm{~Hz}, 2 \mathrm{kHz}, 10$ $\mathrm{kHz}$ and $40 \mathrm{kHz}$. The waveform output of experimentally 
designed phase shift oscillator and the one obtained through simulation is shown in Fig. 5 for two frequencies $f=$ $40 \mathrm{kHz}$ and $f=500 \mathrm{~Hz}$. The frequency of the output waveform obtained theoretically and experimentally is presented in Table II.

TABLE II: THEORETICAL AND EXPERIMENTALLY OBSERVED VALUES OF FREQUENCY OF OSCILLATION

\begin{tabular}{|c|c|c|c|c|c|c|c|c|c|c|}
\hline S.No. & \begin{tabular}{c|}
$\mathrm{R}_{1}$ \\
$(\mathrm{k} \Omega)$
\end{tabular} & \begin{tabular}{c|}
$\mathrm{R}_{\mathbf{2}}$ \\
$(\mathrm{k} \Omega)$
\end{tabular} & $\begin{array}{c}\mathrm{R}_{\mathrm{C}} \\
(\mathrm{k} \Omega)\end{array}$ & $\begin{array}{c}\mathrm{R}_{\mathrm{E}} \\
(\mathrm{k} \Omega)\end{array}$ & $\begin{array}{l}\mathrm{C}_{\mathrm{E}} \\
(\mu \mathrm{F})\end{array}$ & $\begin{array}{c}\mathrm{R} \\
(\mathrm{k} \Omega)\end{array}$ & $\begin{array}{c}\mathrm{C} \\
(\mu \mathrm{F})\end{array}$ & $\begin{array}{l}\mathrm{V}_{\mathrm{CC}} \\
\text { (V) }\end{array}$ & $\begin{array}{c}f_{\text {theoretical }} \\
(\mathrm{kHz})\end{array}$ & $\begin{array}{c}f_{\text {experimental }} \\
(\mathrm{kHz})\end{array}$ \\
\hline 1 & $\begin{array}{c}34 \\
\text { (33) }\end{array}$ & $\begin{array}{r}14.55 \\
(15)\end{array}$ & $\begin{array}{l}1.36 \\
(1.3)\end{array}$ & $\begin{array}{l}1.14 \\
(1)\end{array}$ & $\begin{array}{l}7.01 \\
(10)\end{array}$ & $\begin{array}{l}3.25 \\
(3.3)\end{array}$ & $\begin{array}{c}0.01 \\
(0.01)\end{array}$ & 10 & 2 & 1.96 \\
\hline 2 & $\begin{array}{c}82 \\
(82)\end{array}$ & $\begin{array}{c}54.42 \\
(56)\end{array}$ & $\begin{array}{l}1.36 \\
(1.3)\end{array}$ & $\begin{array}{c}3.64 \\
(3.6)\end{array}$ & $\begin{array}{l}2.19 \\
(2.2)\end{array}$ & $\begin{array}{c}0.65 \\
(0.68)\end{array}$ & $\begin{array}{c}0.01 \\
(0.01)\end{array}$ & 20 & 10 & 9.6 \\
\hline 3 & $\begin{array}{l}34 \\
\text { (33) }\end{array}$ & $\begin{array}{r}14.55 \\
(15)\end{array}$ & $\begin{array}{l}1.36 \\
(1.3)\end{array}$ & $\begin{array}{l}1.14 \\
(1)\end{array}$ & $\begin{array}{l}7.01 \\
(10)\end{array}$ & $\begin{array}{c}13 \\
(13)\end{array}$ & $\begin{array}{c}0.01 \\
(0.01)\end{array}$ & 10 & 0.5 & 0.481 \\
\hline 4 & $\begin{array}{c}34 \\
(33)\end{array}$ & $\begin{array}{r}14.55 \\
(15)\end{array}$ & $\begin{array}{l}1.36 \\
(1.3)\end{array}$ & $\begin{array}{l}1.14 \\
(1)\end{array}$ & $\begin{array}{l}7.01 \\
(10)\end{array}$ & $\begin{array}{l}0.16 \\
(0.16)\end{array}$ & \begin{tabular}{|c|}
0.01 \\
$(0.01)$
\end{tabular} & 10 & 40 & 40.3 \\
\hline 5 & $\begin{array}{c}34 \\
(33)\end{array}$ & $\begin{array}{r}14.55 \\
(15)\end{array}$ & $\begin{array}{l}1.36 \\
(1.3)\end{array}$ & $\begin{array}{l}1.14 \\
(1)\end{array}$ & $\begin{array}{l}7.01 \\
(10)\end{array}$ & $\begin{array}{l}16.25 \\
(16)\end{array}$ & $\begin{array}{l}0.01 \\
(0.01)\end{array}$ & 10 & $\begin{array}{c}\text { Oscillation } \\
\text { not possible }\end{array}$ & $\begin{array}{c}\text { No oscillation } \\
\text { observed }\end{array}$ \\
\hline
\end{tabular}

(a) Frequency: $40 \mathrm{kHz}$ using simulation

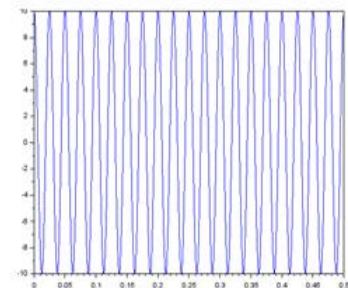

(b) Frequency: $500 \mathrm{~Hz}$ using simulation

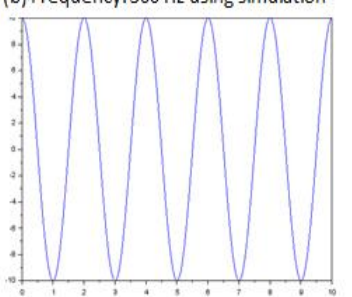

Fig. 5. Waveform output of phase shift oscillator obtained using: simulation ((a) \& (b)) and experimentally designed circuit ((c) \& (d)).

The experimentally obtained results are in close proximity to the theoretically obtained ones. The maximum deviation between the theoretical and experimentally obtained frequency is about $4 \%$ and is attributed to the tolerances (10\%) of the components [27], [28]. It is worth to mention here that with transistor $B C 547 B$, the oscillator circuit with wave output frequency less than $500 \mathrm{~Hz}$ (say $400 \mathrm{~Hz}$ ) cannot be designed. This is because the condition on the gain of the CE amplifier given by equation (2) fails for frequency less than $500 \mathrm{~Hz}$. The same is observed in experimentally realized circuit.

The usage of mathematical software to design and analyze various electronic circuits has been explored earlier and found to be an important tool as it provides many benefits that traditional way of cook book method cannot provide [10]-[12], [29]. Wanhammar has shown that electronic op-amp based circuits at undergraduate level could be beautifully realized with the help of mathematical programs written in MATLAB [29]. Such analysis can be done for various other circuits mentioned in the syllabi of Physics and Electronics undergraduate courses using appropriate mathematical codes.

\section{A. Survey Report and Analysis}

The present study also aims to gather what the students stance about the idea of introducing the use of mathematical programs as a pre lab tool for designing and analyzing electronic circuits and their experience with the task of designing an important electronic circuit given to them using a mathematical code. The authors used Google Forms to circulate an online questionnaire, the link for which was conveyed through different social media platforms. The questionnaire consisted of 7 questions to gauge the student's perception about their experience and viewpoint on use of mathematical programs. Five-point Likert scale was used to calibrate the levels of agreement or disagreement with the statements and for data analysis, the following values were assigned to different levels:

\section{Strongly Agree - 5, Agree - 4, Neutral - 3, Disagree - 2, Strongly Disagree - 1 .}

The reliability and validity of the aimed questionnaire in the present study was first examined. Reliability refers to the accuracy or precision of a measuring instrument [30] and defines the level of consistency or dependability of the measure of construct. Amongst several measures, internal consistency is a widely used measure for assessing scale reliability. Internal consistency assesses whether several items that propose to measure the same construct produce similar scores. The internal consistency of the instrument has been assessed using Cronbach's Alpha. Whitely [31] states that Cronbach's alpha score exceeding 0.70 indicates a strong item co-variance. The Cronbach's alpha score of acceptance of mathematical programs as a prelab activity is found to be 0.820028627 , which indicates that the instrument can be presumed to be reliable.

Validity can be defined as the extent to which data collection methods accurately measure what they were intended to measure. For the current study, we have used face validity. Accordingly, the questionnaire has been validated by the two major stakeholders: the students and the professors. Before collection of data, feedback regarding the validity was taken from professors and students from the electronics and mathematics field. The obtained Cronbach's alpha score and approval of the questionnaire to address the intended research issue from the masters in field validate the use of questionnaire as an able instrument to gauge the students' stance.

More than 500 Physics and Electronics undergraduate students from different colleges of University of Delhi participated in this survey. The opinion on adoption of mathematical programs as a methodological tool in practical labs for the design and analysis of electronic circuits was sought. Most of the respondents answered in favor of the statement that programming simulation tools are easier to use for design and analysis of electronic circuits. This is because they are familiar with the use of mathematical programs, as the latter is an integral part of their course curriculum. The ease of use of mathematical programs in designing and analysis of electronic circuits has also been experienced earlier by many researchers [10]-[12], [29]. When asked about the flexibility provided by the simulation tools, a majority of respondents answered in favor of using programming tools in comparison to doing the designing and 
analysis manually in the labs, as these tools comfortably provide a route that allows for cycling different scenarios of the circuit design [10], [11]. When asked about deeper understanding of the concept via mathematical programs, all the respondents were lying in the category of positive responses: Agree or Strongly Agree. Probably realizing the same, Wanhammar also came up with his work on designing op-amp based circuit using MATLAB programming tool [29] Also, a majority of survey respondents agreed to the statement that use of mathematical program as a pre lab activity is very satisfying and stimulating. All these results are clearly depicted in Fig. 6.

Most of the students were able to realize the circuit given in the task, successfully in the physical laboratory using the designing parameters obtained through the mathematical program. The obtained results were in good agreement with the results shown by the mathematical program.

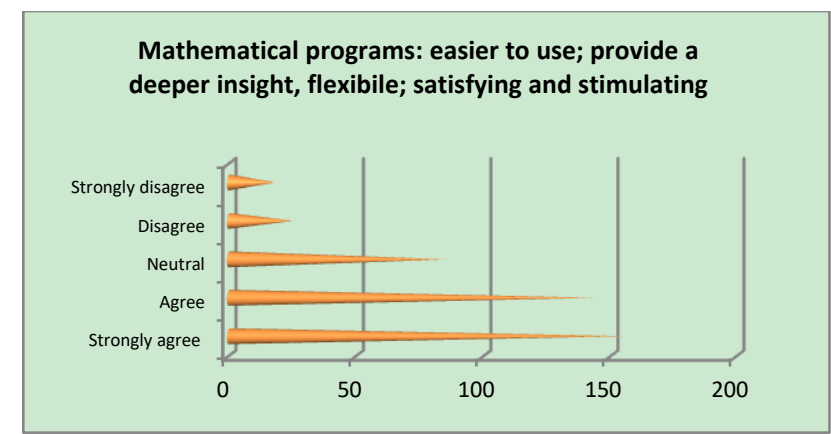

Fig. 6. Opinion on ease of use of mathematical programs in designing and analysis as compared to doing it manually.

Most of the participants of the survey were found to be neutral and a significant number was found to be inclined to believe that there is a need of inclusion of mathematical programs in science undergraduate curriculum for design and analysis of electronic circuits. This response is presented in Table III. It may be seen from Table III that obtained response on inclusion of mathematical programs is negatively skewed with median and mode both as unity, indicating more positivity towards acceptance of use of mathematical programs. It is also evident from Table III that more than half of the respondents were in favor of introducing this methodological approach formally in their curriculum.

TABLE III: INCLUSION OF MATHEMATICAL PROGRAMS AS AN ESSENTIAL TOOL IN CIRCUIT ANALYSIS AND DESIGNING IN SCIENCE UNDERGRADUATE CURRICULUM

\begin{tabular}{|l|r|}
\hline Mean & 0.552083333 \\
\hline Standard Error & 0.051019844 \\
\hline Median & 1 \\
\hline Mode & 1 \\
\hline Standard Deviation & 0.499890339 \\
\hline Sample Variance & 0.249890351 \\
\hline Kurtosis & -1.99675772 \\
\hline Skewness & -0.212812632 \\
\hline
\end{tabular}

The data from the Likert type questions indicates that the use of mathematical simulation tools is well perceived by most of the students owing to its contribution in saving time and helping them enhance the learning experience. It also gives the students a feeling of satisfaction and motivates them to realize the circuits manually. The only drawback with the use of mathematical program is that the user should have access to the basic computing device i.e. computer or laptop.

Hence the proposed approach in the present study can be instrumental for educating the practical component of circuit theory to science undergraduate students. This technique is cost effective as it does not require expensive hardware and software. Moreover, the students need not put extra time and effort in learning this tool. The realization of good and swift design results using simulation tools facilitates stepping up of practical component learning and enhancement of its quality.

\section{CONCLUSION}

The article throws light on the potential use of mathematical programs in making the design and analysis of electronic circuits easier for learners. The success of programming platform is gauged through an online survey, where the respondents were asked to complete a given task using a mathematical program and answer a few questions based upon their experience in doing so. Around 93\% of the survey respondents show positivity towards the use of mathematical programs in the practical papers related to circuit theory. The survey respondents express their agreement to the fact that the use of mathematical programs provides more flexibility in terms of changing the variables effortlessly, saves time and things work out decently well. It also gives them user satisfaction and stimulates them to complete the task of designing flawlessly. As per the results of the conducted survey, a majority $(55 \%)$ of science undergraduate student-respondents are also in favor of formal inclusion of the use of mathematical programs as a complementary methodological approach in the practical component related to papers on circuit theory. Although this analysis shows that the use of mathematical software in circuit theory has been very well accepted by the students yet the present study is restricted to the use of mathematical programs in circuit theory analysis only. The present work has not checked the possibility of introducing mathematical programs as an aid in strengthening the practical component learning in other disciplines. As a result, the conclusion in this study does not intend to define the over-all usefulness of mathematical programs. Therefore, in future, researchers may carry out further investigations to amplify the present work and reach the attributes needed.

\section{CONFLICT OF INTEREST}

The authors declare that they have no conflicts of interest.

\section{AUTHOR CONTRIBUTIONS}

Conceptualization: NDS, JB and MB; Formal Analysis-NDS; Investigation: NDS, MB; Methodology-NDS, JB, MB; Statistical Analysis- JB; Writing original draftNDS; writing review and editing- JB; All authors had approved the final version.

\section{REFERENCES}

[1] S. Dhawan, "Online learning: A panacea in the time of COVID-19 crisis," Journal of Educational Technology Systems, vol. 49, no. 1, pp. 5-22, 2020. 
[2] L. Mishra, T. Gupta, and A. Shree, "Online teaching-learning in higher education during lockdown period of Covid-19 pandemic," International Journal of Educational Research Open, vol. 1, p. 100012 2020.

[3] S. Pokhrel and R. Chhetri, "A literature review on impact of COVID-19 pandemic on teaching and learning," Higher Education for the Future, vol. 8, no. 1, pp. 133-141, 2021.

[4] M. N. Singh, "Inroad of digital technology in education: Age of digital classroom," Higher Education for the Future, vol. 8, no. 1, pp. 20-30, 2021.

[5] D. Ibrahim, "Engineering simulation with MATLAB: Improving teaching and learning effectiveness," Procedia Computer Science, vol. 3, pp. 853-859, 2011.

[6] M. Habibi, C. Fearing, and M. Muslu, "Pros and cons of laboratory methods used in engineering education," ASEE's 123rd Annual Conference \& Exposition, New Orleans, LA, paper ID \# 15965, June 2016.

[7] J C. Prather and S M. Wentworth, "Design of experiment in junior-level RF systems lab," ASEE's 125th Annual Conference \& Exposition, Salt Lake City, UT, paper ID \# 22334, June 2018.

[8] R. Hossain, M. Ahmed, H. U. Zaman, and M. A. Nazim, "A comparative study of various simulation software for design and analysis of operational amplifier based integrator circuits," in Proc. 8th Annual Industrial Automation and Electromechanical Engineering Conference (IEMECON), pp. 278-282, 2017.

[9] X. Wang, C. Jin, J. K. Eshraghian et al., "A behavioral SPICE model of a binarized memristor for digital logic implementation," Circuits Syst Signal Process, vol. 40,pp. 2682-2693, 2021.

[10] N. Hinov and T. Hranov, "Using mathematical software to design power electronics converter," AIP Conference Proceedings, December 2017.

[11] C.-F. Huang, L.-Z. He, and Z.-X. Han, "The application of Mathematical Software," in Proc. the 2nd International Conference on Information Science and Engineering, pp. 1578-1581, 2010.

[12] Z. D. Wang, Mathematical Software and Mathematical Experiment, Beijing, Science Press, 2004.

[13] H. Kaur, "Assessing technical efficiency of the indian higher education: An application of data envelopment analysis approach", Higher Education for the Future, May 2021.

[14] N. Kapilan, P. Vidhya, and X.-Z. Gao, "Virtual laboratory: A boon to the mechanical engineering education during Covid-19 pandemic," Higher Education for the Future, vol. 8, no. 1, pp. 31-46, 2021.

[15] T. F. Schubert and E. M. Kim, Fundamentals of Electronics: Book 4 Oscillators and Advanced Electronics Topics, Morgan \& Claypool Publishers, 2016.

[16] B. V. Rao et al., Electronic Circuit Analysis, Pearson, India, 2012.

[17] G. Komanapalli, R. Pandey, and N. Pandey, "New sinusoidal oscillator configurations using operational transresistance amplifier," Int J Circ Theor. Appl., pp. 1-20, 2019.

[18] T. W. Martin, A. Azemi, D. Hewett, and C. P. Schneider, "PSpice in electrical engineering laboratories," in Proc. the ASEE Annual Conference, pp. 1307-1308, 1992

[19] A. Porębska et al., "The use of mathematical programs and numerical methods in teaching selected topics in circuit theory based on Maple and MATLAB," Global Journal of Engineering Education, vol. 13, no. 3, pp. 132-139, 2011

[20] J. A. Oppong, B.-A. Vivian, and E. Antiaye, "Evaluating the benefits of computer aided-design (CAD) in fashion education, the case of Accra Polytechnic," Journal of Education and Practice, vol. 4, no. 21, pp. 73-79, 2013

[21] D. Guney, "The importance of computer-aided courses in architectural education," Procedia - Social and Behavioral Sciences, vol. 176, pp. $757-765,2015$

[22] R. Boylestad and N. L. Louis, Electronic Devices and Circuit Theory, Pearson 11th Edition 2015.
[23] A. Kaewpoonsuk, A. Sri-in, and R. Katman, "Amplitude control of twin-T and Phase-shift oscillators based on direct feedback control technique," NU Science Journal, vol. 10 no. 2, pp. 10-17, 2013.

[24] R. Senani et al., Sinusoidal Oscillators and Waveform Generators Using Modern Electronic Circuit Building Blocks, Springer International Publishing, AG: Cham, Switzerland, 2016.

[25] T. L. Floyd, Electronic Devices (Conventional Current Version), Global Edition, 10th Edition, Pearson, 2018.

[26] J. Millman, C. Halkias, and C. Parikh, Millman's Integrated ELECtronics - Analog and Digital Circuit and Systems, McGraw Hill Education, 2017.

[27] G. F. Zhai, Y. G. Zhou, X. R. Ye, and B. Hu, "A method of multi-objective reliability tolerance design for electronic circuits," Chinese Journal of Aeronautics, vol. 26, no. 1, pp. 161-170, 2013

[28] I. Farrance and R. Frenkel, "Uncertainty of measurement: A review of the rules for calculating uncertainty components through functional relationships," Clin Biochem Rev., vol. 33, no. 2, pp. 49-75, 2013.

[29] L. Wanhammar, Analog Filters using Matlab, Springer 2009.

[30] F. Kerlinger, Foundations of Behavioral Research, (3rd ed.). Orlando, FL: Harcourt Brace Jovanovich, 1986.

[31] B. E. Whitley, Principals of Research and Behavioural Science, Boston, McGraw-Hill, 2002.

Copyright $\odot 2021$ by the authors. This is an open access article distributed under the Creative Commons Attribution License which permits unrestricted use, distribution, and reproduction in any medium, provided the original work is properly cited (CC BY 4.0).

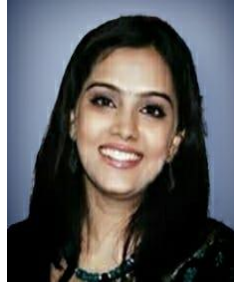

Namrata Dewan Soni completed her $\mathrm{PhD}$ in physics in 2008 from University of Delhi, India. Presently, Dr. Soni is an associate professor at the Department of Physics and Electronics in Hans Raj College, University of Delhi. She is a gold medalist in physics and a proud recipient of "Teaching excellence award". She has also authored a book on Tensors. Her research work is in the area of condensed matter physics and is focused on temperature stability of surface acoustic wave (SAW) devices and sensors. Her other research interests are in the growth and characterization of metal oxide films for their structural, optical and dielectric properties. She has published more than 10 articles in journals of international repute and has developed various emodules for undergraduate Physics students.

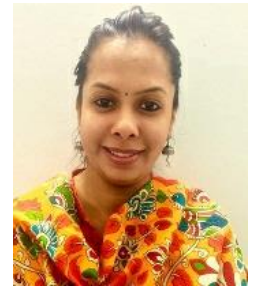

Jyoti Bhola completed her $\mathrm{PhD}$ in mathematics in 2010 from University of Delhi, India. Presently, Dr. Bhola is an associate professor at the Department of Mathematics in Hans Raj College, University of Delhi. She is a gold medalist in mathematics. She has authored two text books of mathematics and her areas of her research interests include functional analysis, differential equations, statistical analysis and mathematical modelling. She has published more than 10 articles in journals of international repute and has developed various e- modules for undergraduate Mathematics students.

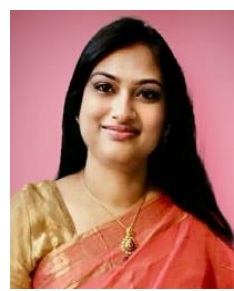

Mona Bhatnagar is an associate professor in the Department of Physics \& Electronics at Hansra College has been a teaching faculty since 1989 . A Delhi University topper and a gold medalist in M.Sc. electronics, she is also a recipient of Dr. S. Radha Krishnan Memorial National Teacher Award for the Best Teacher in 2016 and Women Excellence Award in Education in 2017. She has to her credit 7 technical paper publications. She has been a co-principal investigator in 3 projects funded by DST, DBT \& DU. Her doctoral research was in the field of thin films for photovoltaic applications. 